\begin{tabular}{|c|c|c|}
\hline & $\begin{array}{c}\text { Port Said Engineering Research Journal } \\
\text { Faculty of Engineering - Port Said University } \\
\text { Volume 16 No. } 2 \text { pp.: 29:40 }\end{array}$ \\
\hline
\end{tabular}

\title{
Vibration Isolation of A Symmetric Rigid Plate Using Pair Pre-bent Struts with Intermediate Bonded Filler at Each Corner under Static and Dynamic Axial Excitation
}

\author{
Aly El-Kafrawy \\ Port-Said University Department of \\ Production Engineering and \\ Machine Design \\ Port- Said, ARE \\ dr_eng_aly@hotmail.com
}

\author{
Anwar Kandil \\ Port-Said University \\ Department of Production \\ Engineering and Machine Design \\ Port- Said, ARE \\ anwarkandil@hotmail.com
}

\author{
Mostafa Helaly \\ Alexandria University \\ Department of Production \\ Engineering \\ Faculty of Engineering, \\ ARE Alexandria, \\ mohelaly@globalnet.com
}

\author{
Abu-Bakr Omar \\ Suez Canal University \\ Department of Production \\ Engineering and Machine Design \\ Ismailia, ARE \\ abubakr31869@yahoo.com
}

\begin{abstract}
The objective of this paper is to study the influence of vibration isolators in the form of post-buckled elastic struts. A mathematical model is introduced consisting of pre-bent post-buckled pairs strut with intermediate bonded filler acting as vibration isolators supporting a symmetric rigid plate. The model is subject to axial harmonic excitation at the base, and allowed to displace laterally with respect to axial center line of plate. The displacement transmissibility is the governing parameter of the isolator's effectiveness. The transmissibility is calculated over a wide range of frequencies and plotted in form of design charts. These plots showed the ranges of frequencies, at which isolation can be maintained. The system resonance frequencies can be easily depicted from design graphs. The present study reveals that at resonance frequencies the most effective transmissibility is well below unity. Vibration characteristics are determined under specific frequencies such that the physical behavior of the system can be thoroughly analyzed. All variables used are normalized, such that the results aren't dependent on any material or geometric property, such as the modulus of elasticity of the material, section modulus of the used profile, or the length of the strut. In this way, the obtained results can be applied over a wide range of elastic materials, regardless of the type of material or section properties.
\end{abstract}

Keywords Transmissibility, Euler elastic buckling, Vibration isolation, Struts, intermediate bonded filler, post-buckled

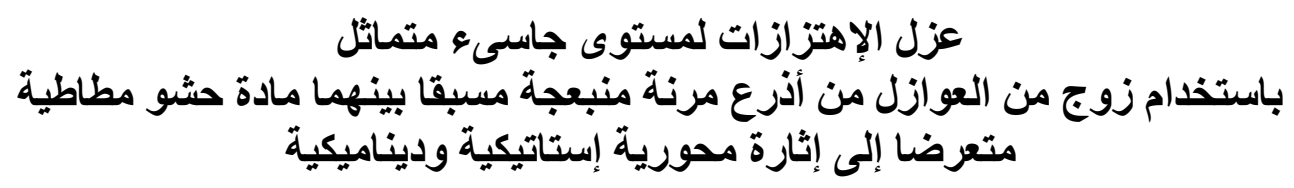

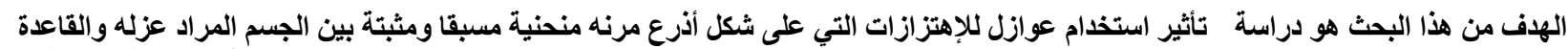

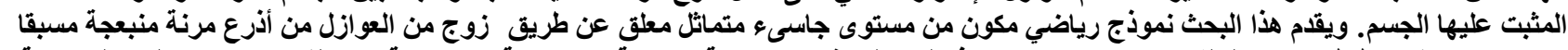

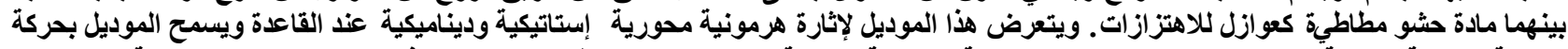

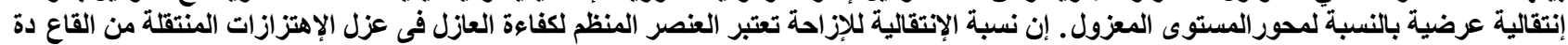

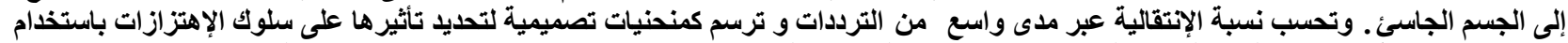

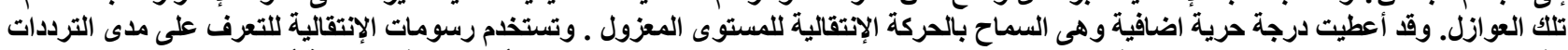

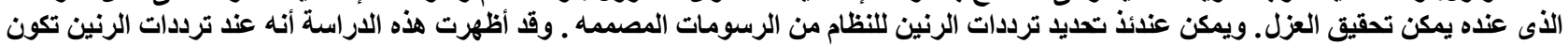

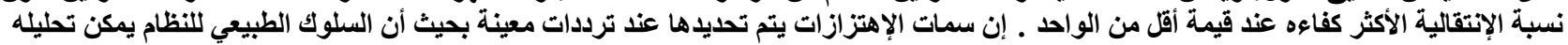

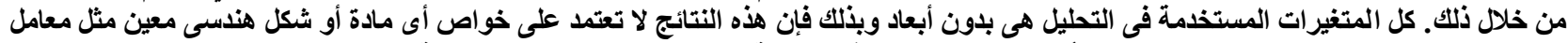

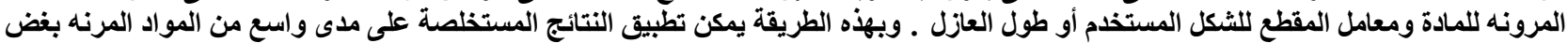

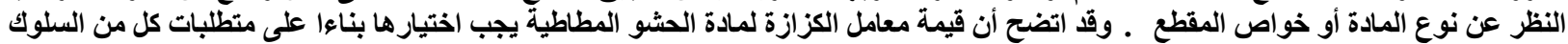

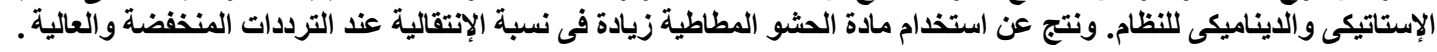




\section{List of symbols}

It's worth to mention that capital letters are denoted to dimensional variables, while small letters are thought for normalized non dimensional quantities. The dimensional and dimensionless variables used in the present paper are:

$\mathrm{A}_{1} \quad$ Distance from plate center gravity to strut 1 and strut 3 in $\bar{X}$-direction (m)

$a_{1} \quad$ Dimensionless distance from plate center gravity to strut 1 and strut 3 in $\bar{X}$-direction (-)

$\mathrm{A}_{2} \quad$ Distance from plate center gravity to strut 2 and strut 4 in $\bar{X}$-direction (m)

$\mathrm{a}_{2} \quad$ Dimensionless distance from plate center gravity to strut 2 and strut 4 in $\bar{X}$-direction (-)

$A_{b} \quad$ Surface area of the block $\left(\mathrm{m}^{2}\right)$

$a_{b} \quad$ Dimensionless surface area of the block (-)

$A_{p} \quad$ Surface area of the plate $\left(\mathrm{m}^{2}\right)$

$a_{p} \quad$ Dimensionless surface area of the plate (-)

$\mathrm{B}_{1} \quad$ Distance from plate center gravity to strut 1 and strut 2 in $\bar{Y}$-direction (m)

$\mathrm{b}_{1} \quad$ Dimensionless distance from plate center gravity to strut 1 and strut 2 in $\bar{Y}$ - direction (-)

$\mathrm{B}_{2} \quad$ Distance from plate center gravity to strut 3 and strut 4 in $\bar{Y}$-direction (m)

$b_{2} \quad$ Dimensionless distance from plate center gravity to strut 3 and strut 4 in $\bar{Y}$ - direction (-)

C External damping coefficient per unit length of strut (N.s/m)

c Dimensionless external damping coefficient per unit length of strut (-)

$\mathrm{C}^{\mathrm{c}} \quad$ Distance from bottom plate surface to C.G. of the plate $(\mathrm{m})$

$\mathrm{c}^{\mathrm{c}}$ Dimensionless distance from bottom plate surface to C.G. of the plate (-)

d Subscript used to indicate variables resulting from dynamic analysis

$\mathrm{D}_{\mathrm{d}} \quad$ Depth of the block (m)

$d_{d} \quad$ Dimensionless depth of the block (-)

dS Infinite small length element along the arc of the strut $(\mathrm{m})$

ds Dimensionless infinite small length element along the arc of the strut (-)

$\mathrm{dS}_{\mathrm{i}} \quad$ Infinite small length element along the arc of the strut in the $i^{\text {th }}$ isolator $(\mathrm{m})$

$\mathrm{ds}_{\mathrm{i}}$ Dimensionless small element of length along the arc of the strut in the $\mathrm{i}^{\text {th }}$ isolator (-)

$\mathrm{dX}$ Projection of $\mathrm{dS}$ in the $\overline{\mathrm{X}}$-direction (m)

$\mathrm{dx}$ Dimensionless projection of $\mathrm{ds}$ in $\overline{\mathrm{X}}$-direction (-)

$\mathrm{dX}_{\mathrm{i}, \mathrm{st}}$ projection of $\mathrm{dS}_{\mathrm{i}}$ in $\overline{\mathrm{X}}$-direction (m)

$\mathrm{dx}_{\mathrm{i}, \mathrm{st}}$ Dimensionless projection of $\mathrm{ds}_{\mathrm{i}}$ in $\overline{\mathrm{X}}$-direction (-)

$\mathrm{dY}$ Projection of $\mathrm{dS}$ in $\overline{\mathrm{Y}}$-direction $(\mathrm{m})$

dy Dimensionless projection of ds in $\bar{Y}$-direction (-)

$d Y_{i, s t}$ Projection of $d S_{i}$ in the $\bar{Y}$-direction (m)

$\mathrm{dy}_{\mathrm{i}, \mathrm{st}}$ Dimensionless projection of $\mathrm{ds}_{\mathrm{i}}$ in the $\overline{\mathrm{Y}}$ direction (-)

E Modulus of elasticity of elastic material of strut (assumed to be the same for all struts) (GPa)

g Gravity acceleration $\left(\mathrm{m} / \mathrm{s}^{2}\right)$

$\mathrm{H}_{\mathrm{o}} \quad$ Height of plate from the base, the equilibrium height (m) $\mathrm{h}_{\mathrm{o}} \quad$ Dimensionless height of plate from the base, the equilibrium height (-)

$\mathrm{H}_{1} \quad$ Thickness of the plate (m)

$\mathrm{h}_{1} \quad$ Dimensionless thickness of the plate (-)

$\mathrm{H}_{2} \quad$ Thickness of the block (m)

$\mathrm{h}_{2} \quad$ Dimensionless thickness of the block (-)

i The isolator counter ranging from $1 \ldots 4(-)$

I Moment of inertia of strut cross-section about the axis of bending (assumed to be the same for all struts) $\left(\mathrm{m}^{4}\right)$

$\overline{\mathrm{I}}_{\mathrm{P}} \quad$ Inertia dyadic

$\mathrm{I}_{\mathrm{x}} \quad$ Principal mass moments of inertia about $\overline{\mathrm{X}}$-axis through center of mass $\left(\mathrm{kg} \cdot \mathrm{m}^{2}\right)$

$\mathrm{i}_{\mathrm{x}} \quad$ Dimensionless principal mass moments of inertia about $\bar{X}$-Axis through center of mass (-)

$\mathrm{I}_{\mathrm{Y}}$ Principal mass moments of inertia about $-\overline{\mathrm{Y}}$ axis through center of mass $\left(\mathrm{kg} . \mathrm{m}^{2}\right)$

$\mathrm{i}_{\mathrm{y}} \quad$ Dimensionless principal mass moments of inertia about $-\overline{\mathrm{Y}}$-axis through center of mass (-)

j Number of the horizontal springs (-)

$\mathrm{K} \quad$ Spring stiffness $(\mathrm{N} / \mathrm{m})$

$\mathrm{k} \quad$ Dimensionless spring stiffness (-)

$\mathrm{K}_{\mathrm{j}} \quad$ Stiffness of the eight horizontal attached to the plate, $\mathrm{j}=1: 8(\mathrm{~N} / \mathrm{m})$

$\mathrm{k}_{\mathrm{j}} \quad$ Dimensionless stiffness of the eight horizontal attached to the plate, $\mathrm{j}=1: 8(-)$

L Length of strut (m)

M Bending moment acting on the strut (N.m)

$\mathrm{m}$ Dimensionless bending moment acting on the strut (-)

$\mathrm{M}_{1} \quad$ Plate mass (kg)

$\mathrm{m}_{1} \quad$ Dimensionless plate mass (-)

$\mathrm{M}_{2} \quad$ Block mass (kg)

$\mathrm{m}_{2} \quad$ Dimensionless block mass (-)

$\mathrm{M}_{\mathrm{i}, \mathrm{st}}$ Bending moment acting on the strut for the $\mathrm{i}^{\text {th }}$ isolator (N.m)

$\mathrm{m}_{\mathrm{i}, \mathrm{st}}$ Dimensionless bending moment acting on the strut for the $i^{\text {th }}$ isolator (-)

$\mathrm{P}$ Horizontal component of force acting on the strut at $\mathrm{S}=0(\mathrm{~N})$

$\mathrm{p}$ Dimensionless horizontal component of force acting on the strut at $\mathrm{s}=0(-)$

$\mathrm{P}_{\mathrm{i}, \mathrm{st}}$ Component of force acting in $\overline{\mathrm{X}}$-direction on the strut for the $\mathrm{i}^{\text {th }}$ isolator $(\mathrm{N})$

$\mathrm{p}_{\mathrm{i}, \mathrm{st}}$ Dimensionless component of force acting in $\overline{\mathrm{X}}$ direction on the strut for the $\mathrm{i}^{\text {th }}$ isolator (-)

$\mathrm{P}_{\mathrm{o}} \quad$ Applied load from the rigid plate on the strut, (the classical Euler critical load, $\left.\mathrm{P}_{\mathrm{cr}}\right)(\mathrm{N})$

$\mathrm{p}_{\mathrm{O}} \quad$ Dimensionless applied load from the rigid plate on the strut, (the classical Euler critical load, $\mathrm{P}_{\mathrm{cr}}$ ) $(-)$

$\mathrm{P}_{\mathrm{w}} \quad$ Ratio of the weight $\mathrm{W}$ to the weight of the strut $\mu \mathrm{gl}(-)$

Q Vertical component of force in the strut at $\mathrm{S}=0$ (N)

q Dimensionless vertical component of force in the strut at $\mathrm{s}=0(-)$

$\mathrm{Q}_{\mathrm{i}, \mathrm{st}}$ Component of force acting in $\overline{\mathrm{Y}}$ - Direction on the strut in the $i^{\text {th }}$ isolator $(\mathrm{N})$

$\mathrm{q}_{\mathrm{i}, \mathrm{st}}$ Dimensionless component of force acting in $\overline{\mathrm{Y}}$ Direct. on the strut in the $\mathrm{i}^{\text {th }}$ isolator (-) 
$\mathrm{U}(\mathrm{T})$ Position of the point with respect to time $\mathrm{T}(\mathrm{m})$
$\mathrm{u}(\mathrm{t})$ Dimensionless position of the point with respect to time $\mathrm{t}(-)$

$\mathrm{V}_{\mathrm{s}, \mathrm{i}} \quad$ Potential energy in the springs $(\mathrm{N})$

W Weight of the supported load (full rigid plate) (N)

w Dimensionless weight of the supported load (-)

$\mathrm{W}_{\mathrm{d}} \quad$ Width of the block (m)

$\mathrm{w}_{\mathrm{d}} \quad$ Dimensionless width of the block (-)

Yo Initial buckling of the strut $(\mathrm{m})$

$y_{0} \quad$ Dimensionless initial buckling of the strut (-)

$\mathrm{Y}_{\mathrm{L} 1} \quad$ Strut $1 \bar{Y}$-lateral movement (m)

$\mathrm{y}_{\mathrm{L} 1} \quad$ Dimensionless strut $1 \overline{\mathrm{Y}}$-lateral movement (-)

$\mathrm{Y}_{\mathrm{L} 2} \quad$ Strut $2 \overline{\mathrm{Y}}$-lateral movement (m)

$\mathrm{y}_{\mathrm{L} 2}$ Dimensionless strut $2 \overline{\mathrm{Y}}$ - lateral movement (-)

$\mathrm{Y}_{\mathrm{L} 3} \quad$ Strut $3 \overline{\mathrm{Y}}$-lateral movement (m)

$\mathrm{y}_{\mathrm{L} 3} \quad$ Dimensionless strut $3 \overline{\mathrm{Y}}$ - lateral movement (-)

$\mathrm{Y}_{\mathrm{L} 4} \quad$ Strut $4 \overline{\mathrm{Y}}$-lateral movement (m)

$\mathrm{y}_{\mathrm{L} 4} \quad$ Dimensionless strut $4 \overline{\mathrm{Y}}$ - lateral movement (-)

$\mathrm{Y}_{\mathrm{b} 1} \quad$ Strut $1 \overline{\mathrm{Y}}$ - buckling movement $(\mathrm{m})$

$\mathrm{y}_{\mathrm{b} 1} \quad$ Dimensionless strut $1 \overline{\mathrm{Y}}$-buckling movement (-)

$\mathrm{Y}_{\mathrm{b} 2} \quad$ Strut $2 \overline{\mathrm{Y}}$ - buckling movement $(\mathrm{m})$

$\mathrm{y}_{\mathrm{b} 2} \quad$ Dimensionless strut $2 \overline{\mathrm{Y}}$-buckling movement (-)

$\mathrm{Y}_{\mathrm{b} 3} \quad$ Strut $3 \overline{\mathrm{Y}}$ - buckling movement (m)

$\mathrm{y}_{\mathrm{b} 3} \quad$ Dimensionless strut $3 \overline{\mathrm{Y}}$-buckling movement (-)

$\mathrm{Y}_{\mathrm{b} 4} \quad$ Strut $4 \overline{\mathrm{Y}}$ - buckling movement (m)

$\mathrm{y}_{\mathrm{b} 4} \quad$ Dimensionless strut $4 \overline{\mathrm{Y}}$-buckling movement (-)

$\widetilde{Z}$ Distance between centre of each area and OPRQ surface area (m)

$\widetilde{\mathrm{Z}}$ Dimensionless distance between centre of each area and OPRQ surface area (-)

$\alpha \quad$ Aspect ratio of the plate (-)

$\beta_{\mathrm{i}}$ The $\mathrm{i}^{\text {th }}$ isolator factor for strut stiffness modification (-)

$\theta_{\mathrm{i}, \mathrm{st}}$ Angle of the deflected strut in the $\mathrm{i}^{\text {th }}$ isolator measured from $\overline{\mathrm{X}}$-axis $\left[{ }^{\circ}\right]$

$\theta_{\mathrm{o}} \quad$ initial angle $\left[{ }^{\circ}\right]$

$\mu \quad$ Mass per unit length of the strut $(\mathrm{kg} / \mathrm{m})$

$\mu \quad$ Dimensionless mass per unit length of the strut $(-)$

$\bar{\omega}_{\mathrm{P}} \quad$ Angular velocity vector $\left(\mathrm{sec}^{-1}\right)$

$\Omega \quad$ Applied frequency of the axial excitation of the strut base $\left(\mathrm{sec}^{-1}\right)$

$\omega \quad$ Dimensionless applied frequency of the axial excitation of the strut base (-)

\section{Introduction and literature review}

Many modern machinery, such as compressors, internal combustion engines, mining machines, hydraulic, and pneumatic presses, turbo machinery, etc. undergo uncomfortable and even undesirable serious source. These vibrations are in most cases uncontrollable and lead to sudden failure and in turn to a loss of machines availability. Therefore, mechanical engineers in preventive maintenance sections in the industry have the serious job to put these vibrations under control, isolate, and minimize the harmful effects of such unwanted vibrations.

Zhou, N. and Liu, K. (2010) developed a novel vibration isolator. The developed isolator possessed the characteristics of high-static-low-dynamic stiffness (HSLDS) and could act passively or semi-actively. The HSLDS property of the isolator was obtained by connecting a mechanical spring, in parallel with a magnetic spring that was constructed by a pair of electromagnets and a permanent magnet. The mechanical spring was a structural beam whose stiffness exhibited a hardening behavior. The stiffness of the magnetic spring could be positive or negative, depending on the polarity of the current to the electromagnets. Carrella, A. et al. (2009) proposed that the rotor response was reduced by suspending the machine on nonlinear springs. Kovacica, I., Brennanb, M.J., and Waters, T.P. (2008) studied a vibration isolator consisting of a vertical linear spring and two nonlinear pre-stressed oblique springs. The system had both geometrical and physical nonlinearity.

Ibrahim, R.A. (2008) presented a comprehensive assessment of recent developments of nonlinear isolators in the absence of active control means. Carrella, A. et al. (2007) studied a simple system comprising a vertical spring acting in parallel with two oblique springs. It was shown that there was a unique relationship between the geometry and the stiffness of the springs that yields a system with zero dynamic stiffness at the static equilibrium position. Yilmaz, C., Kikuchi, N. (2006) designed stiff and lightweight uniaxial passive vibration isolators that had low stopband frequency. In order to make fair comparisons, stop-band frequencies of various isolator designs were formulated in a general framework. Two new n-degreeof-freedom (n-dof) isolator designs were introduced.

Liu, L.K., Zheng, G.T., Huang, W.H. (2006) introduced an octostrut passive vibration isolation platform with redundancy and applied it to wholespacecraft vibration isolation. This platform was modeled with the Newton-Euler method. Huang, X., Elliott, S.J., and Brennan, M.J. (2003) presented a theoretical and experimental investigation into an active vibration isolation system. Electromagnetic actuators were installed in parallel with each of four passive mounts, which were placed between a flexible equipment structure and a base structure which was either flexible or rigid. Dickens, J.D. and Norwood, C.J. (2001) proposed a two-mass method to determine the four-pole parameters of a uni-directional asymmetrical vibration isolator. It could be regarded as a universal testing procedure applicable to uni- 
directional or bi-directional, and asymmetrical or symmetrical vibration isolators under static load.

Serrand, M. and Elliott, S.J. (2000) described the implementation of an independent two-channel controller based on absolute velocity feedback and its performance in improving the isolation from base vibration of a mounted rigid equipment structure characterized by two-degrees of freedom. Plaut, R.H., Sidbury, J.E., and Virgin, L.N. (2005) analyzed the use of a buckled or pre-bent column with fixed ends as a vibration isolator. The column was designed to have a high axial stiffness under the weight that it supported, so that the static displacement of the weight was not excessive, and then to have a low stiffness during excitation. Isolation of ground vibration has long been considered in the field of nano precision measuring instrument design (Banik, R. and Gweon, D.G. (2008)). They proposed a six-axis hybrid activepassive vibration isolation system which could be used as a tabletop isolator for highly precise measurement and actuation system.

\section{Equilibrium analysis}

\subsection{Equilibrium analysis procedure}

The model studied in this paper is a simple system consisting of four pairs buckled struts with intermediate bonded filler used to support a rigid symmetric plate. The analysis of buckled struts as vibration isolators is based on the use of four pairs from struts connected by a rigid plate at each corner (Jeffers 2005). Jeffers (2005), Alloway (2003), and Plaut et al. (2003) have used strut elements as isolators for fixed-fixed bars underlying axial harmonic displacement excitation. Sidbury (2003) has used the same isolators as used in Jeffers (2005), Alloway (2003), and Plaut et al. (2003) with pinned-pinned end condition. The authors of the present paper have used the same type of isolators as that used in Jeffers (2005), Alloway (2003), Plaut et al. (2003), and Sidbury (2003). However, the end condition is selected within the present analysis as clamped - clamped.

The results determined in Jeffers (2005), Alloway (2003), Plaut et al. (2003), and Sidbury (2003) revealed that the behavior of the buckled strut under axial, harmonic, displacement excitation is similar for both fixed-fixed and pinned-pinned end conditions. In the present paper it has been decided to choose fixed-fixed end conditions, since such system can support much higher load.

First, an analysis of the rigid plate must be performed to determine the relationship between the symmetry weight of the uniform plate and the forces transmitted to each of the four supporting isolators. Secondly, the behavior of each strut must be evaluated in terms of the deflected shape and the forces and moments in the struts, with clamped-clamped ends as done by Jeffers (2005) and Virgin and Davis (2003) as shown in Fig. 1. It should be noted that the model is constrained against any lateral movement except in $\bar{Y}$ direction. If the analyzed model is free to move laterally, the model consisting of pre-bent struts may become unstable and would buckle and sway (Inman (1994) and Favor (2004)).

\subsubsection{Rigid plate analysis}

The plate analyzed in the present work is symmetric. It has the ability to move vertically, rotate about the $\bar{X}$ and $\bar{Y}$-axes and allowed to move laterally in direction- $\bar{Y}$ as shown in Fig. 1. The horizontal movements at the corners of the plate due to such rotations will be ignored in the equilibrium analysis because only small rotations of the plate will be considered. As a result, the plate will be analyzed as a four degree-of-freedom system.

Upon considering the free body diagram of the plate shown in Fig. 2, one apparent observation is that there are four unknown forces, $\mathrm{F}_{1}, \mathrm{~F}_{2}, \mathrm{~F}_{3}$ and $\mathrm{F}_{4}$, acting at the corners of the plate, but only four equations result from the equilibrium. These equations are:

$$
\begin{aligned}
& \mathrm{F}_{1}+\mathrm{F}_{2}+\mathrm{F}_{3}+\mathrm{F}_{4}=\mathrm{W} \\
& -\left(\mathrm{F}_{1}+\mathrm{F}_{2}\right) \mathrm{B}_{1}+\left(\mathrm{F}_{3}+\mathrm{F}_{4}\right) \mathrm{B}_{2}=0 \\
& \left(\mathrm{~F}_{1}+\mathrm{F}_{3}\right) \mathrm{A}_{1}-\left(\mathrm{F}_{2}+\mathrm{F}_{4}\right) \mathrm{A}_{2}=0 \\
& \mathrm{Z}_{\mathrm{O}}-\mathrm{Z}_{\mathrm{P}}-\mathrm{Z}_{\mathrm{Q}}+\mathrm{Z}_{\mathrm{R}}=0
\end{aligned}
$$

Where: $Z_{O}, Z_{P}, Z_{Q}$, and $Z_{R}$ are the vertical displacements at the corners of the plate, which are labeled by $\mathrm{O}, \mathrm{P}, \mathrm{Q}$, and $\mathrm{R}$ when it rotates at some angle about $\overline{\mathrm{X}}$ and $\bar{Y}$ axes.

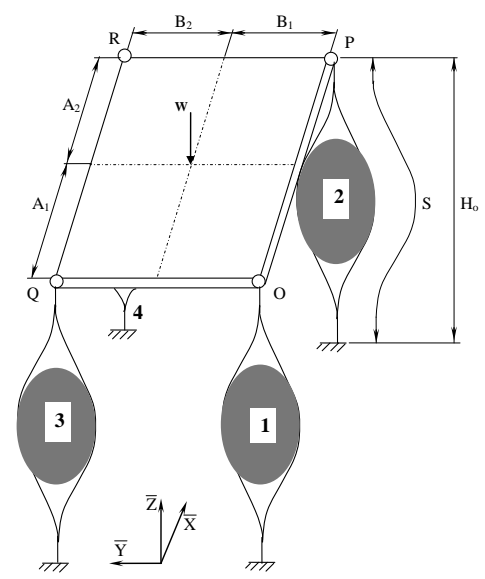

Fig.1 Rigid plate supported by pre-bent struts with intermediate bonded filler.

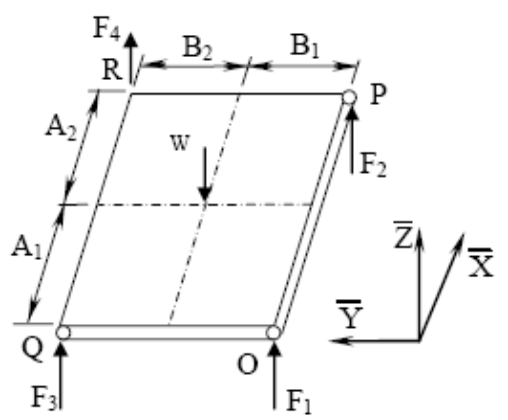

Fig. 2 Free-body diagram of the plate in static equilibrium state

\subsubsection{Vibration isolator analysis}


The axial force applied to the top of each isolator can be determined, it is necessary to examine the forcedisplacement relationship for each isolator. As stated earlier, the isolator, shown horizontally in Fig.3, consists of two struts which are clamped together at both ends and bonded intermediately by a viscoelastic material. The filler contributes both damping and stiffness to the isolator and is represented in Fig. 3 by a series of springs and dashpots acting along the length of the isolator. For simplicity, the isolator is restrained against rotation at both ends and free horizontal ( $\bar{Y}$ direction) displacement without any external laterally force in this direction. This is done because the horizontal displacement of the plate is negligible and this assumption will greatly simplify the problem by allowing the use of symmetry. The additional variables used for the remaining portion of this analysis can be defined as follows. The subscript st is used for static equilibrium analysis. Note that the subscript $i$ is used to denote the current number of isolators.

Before any load is applied to the isolator, each strut has an initial shape with an amplitude $a_{0}$. All four isolators will have the same initial shape and so this part of the analysis holds for each strut in all four isolators. The initial angle $\theta_{\mathrm{o}}(\mathbf{S})$ is assumed as:

$$
\theta_{\mathrm{o}}(\mathrm{S})=\mathrm{a}_{\mathrm{o}} \sin (2 \pi \mathrm{S} / \mathrm{L})
$$

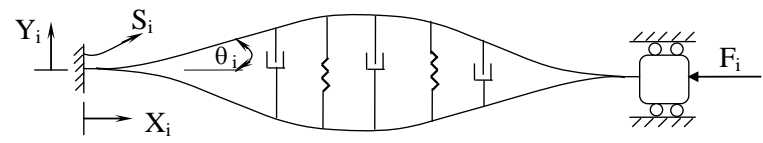

Fig. 3 Model of vibration isolator with bonded filler under static axial load $\mathrm{F}_{\mathrm{i}}$

The initial deflection $Y_{o}(S)$ is equal to the integral of the sine of the initial angle over the length of the strut. For small angles, this is approximately equal to the integral of the initial angle $\theta_{\mathrm{o}}(\mathrm{S})$ over the length of the strut. This gives

$$
\mathrm{Y}_{\mathrm{o}}(\mathrm{S}) \approx \frac{\mathrm{a}_{\mathrm{o}} \mathrm{L}}{2 \pi} \cdot\left(1-\cos \left(\frac{2 \pi \mathrm{S}}{\mathrm{L}}\right)\right)
$$

The struts have the same length and bending stiffness. Hence, the analysis is only carried out on one strut. The other struts represent actually a typical and mirror image of the first. A free-body diagram of an incremental element of the strut is shown in Fig. 4. Under the existing load on the isolator, $F_{i}$, the strut deflects from the initial configuration to a new position $\mathrm{Y}_{\mathrm{i}, \mathrm{st}}(\mathrm{S})$. The following equations are derived to describe the shape of the strut:

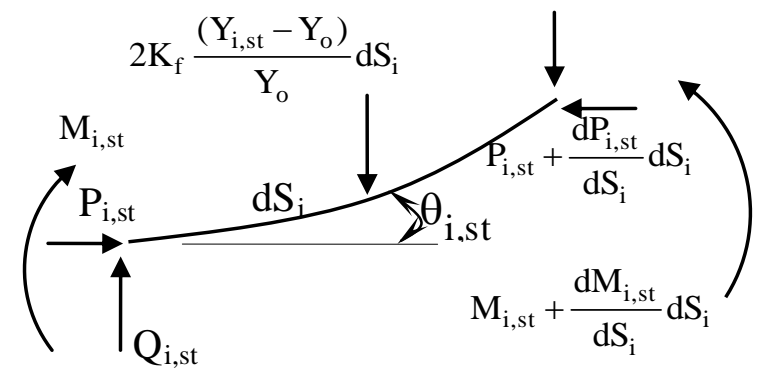

Fig. 4 Free body diagram of an element of the strut in equilibrium case

$$
\begin{aligned}
& \cos \theta_{i, s t}=\frac{d X_{i, s t}}{d S_{i}} \\
& \sin \theta_{i, s t}=\frac{d Y_{i, s t}}{d S_{i}} \\
& \frac{d Q_{i, s t}}{d S_{i}}=\frac{-2 K_{f}}{Y_{o}}\left(Y_{i, s t}-Y_{o}\right) \\
& \left(\frac{d \theta_{i, s t}}{d S_{i}}-\frac{d \theta_{o}}{d S_{i}}\right)=\frac{M_{i, s t}}{\beta_{i} E I} \\
& \frac{d M_{i, s t}}{d S_{i}}=-P_{i, s t} \sin \theta_{i, s t}+Q_{i, s t} \cos \theta_{i, s t}
\end{aligned}
$$

Where $\left(\frac{d \theta_{i, s t}}{d S_{i}}-\frac{d \theta_{o}}{d S_{i}}\right)$ is the change in curvature. Note that the bending stiffness EI for each strut is multiplied by a modification factor $\beta_{\mathrm{i}}$. The stiffness modification factors will be chosen so that the downward deflection at the top of each strut due to the static load $F_{i}$ is the same for all four isolators. In other words, each isolator will have the same initial height $\mathrm{H}_{\mathrm{o}}$ when the system is in equilibrium.

Taking the derivative of equations $(5,6$ and 10) gives:

$$
\begin{aligned}
& \frac{\mathrm{d} \theta_{\mathrm{i}, \mathrm{st}}}{\mathrm{dS}}=\frac{\mathrm{M}_{\mathrm{i}, \mathrm{st}}}{\beta_{\mathrm{i}} \mathrm{EI}}+\frac{2 \pi}{\mathrm{L}} \mathrm{a}_{\mathrm{o}} \cos \left(\frac{2 \pi \mathrm{S}_{\mathrm{i}}}{\mathrm{L}}\right) \\
& \frac{\mathrm{dY_{ \textrm {o } }}}{\mathrm{d} \mathrm{S}_{\mathrm{i}}}=\sin \left[\mathrm{a}_{\mathrm{o}} \sin \left(\frac{2 \pi \mathrm{S}_{\mathrm{i}}}{\mathrm{L}}\right)\right]
\end{aligned}
$$

The struts are made of an elastic material to support a static load up to the critical point, at which the strut buckles. This critical point is known as the Euler buckling load and its value depends upon the support end conditions. For a fixed-fixed strut (not allowed to rotate or to deflect transversely) the critical load is given by $\mathrm{P}_{\mathrm{cr}}=4 \pi^{2} \mathrm{EI} / \mathrm{L}^{2}$. For a pinned-pinned strut (free to rotate transversely) the critical load is given by $\mathrm{P}_{\mathrm{cr}}=\pi^{2} \mathrm{EI} / \mathrm{L}^{2}$, (Inman (1994).

The variables have been normalized so that the analysis provides relevant results for any elastic material, regardless of its geometric and material properties.

The resulting non-dimensional Eqns. (7-13) equations defining the behavior of the $i^{\text {th }}$ strut under static loading (for $0 \leq \mathrm{s} \leq 1$ ) are,

$$
\begin{aligned}
& \cos \theta_{\mathrm{i}, \mathrm{st}}=\frac{\mathrm{dx}_{\mathrm{i}, \mathrm{st}}}{\mathrm{ds}_{\mathrm{i}}} \\
& \sin \theta_{i, s t}=\frac{d y_{i, s t}}{d s_{i}} \\
& \frac{\mathrm{dq}_{\mathrm{i}, \mathrm{st}}}{\mathrm{ds}_{\mathrm{i}}}=-\mathrm{k}_{\mathrm{f}}\left(\frac{\mathrm{y}_{\mathrm{i}, \mathrm{st}}-\mathrm{y}_{\mathrm{o}}}{\mathrm{y}_{\mathrm{o}}}\right) \\
& \frac{d \theta_{i, s t}}{d s_{i}}=\frac{m_{i, s t}}{\beta_{i}}+2 \pi a_{o} \cos \left(2 \pi s_{i}\right) \\
& \frac{\mathrm{dm}_{\mathrm{i}, \mathrm{st}}}{\mathrm{ds}_{\mathrm{i}}}=-\mathrm{p}_{\mathrm{i}, \mathrm{st}} \sin \theta_{\mathrm{i}, \mathrm{st}}+\mathrm{q}_{\mathrm{i}, \mathrm{st}} \cos \theta_{\mathrm{i}, \mathrm{st}}
\end{aligned}
$$




$$
\frac{\mathrm{dy}_{\mathrm{o}}}{\mathrm{ds}_{\mathrm{i}}}=\sin \left[\mathrm{a}_{\mathrm{o}} \sin \left(2 \pi \mathrm{s}_{\mathrm{i}}\right)\right]
$$

The boundary conditions must be established to complement the differential Eqns. (14-19). The fixedfixed end condition of the strut does not allow any rotation at its ends, but it allows only small deflection (lateral movement) in the $\bar{Y}$-direction, Fig. 1.

\subsection{Boundary conditions for static equilibrium state}

The boundary conditions of the treated model in static equilibrium state can be written as follows

$$
\begin{array}{r}
\text { At } \mathrm{s}_{\mathrm{i}, \mathrm{st}}=0 ; \quad \mathrm{x}_{\mathrm{i}, \mathrm{st}}=0, \mathrm{y}_{\mathrm{i}, \mathrm{st}}=0, \text { and } \theta_{\mathrm{i}, \mathrm{st}}=0 \\
\text { (the left, or bottom, end of the strut) } \\
\text { At } \mathrm{s}_{\mathrm{i}, \mathrm{st}}=1 ; \quad \mathrm{y}_{1, \mathrm{st}}=\mathrm{y}_{3, \mathrm{st}}, \quad \mathrm{y}_{2, \mathrm{st}}=\mathrm{y}_{4, \mathrm{st}} \text { and } \theta_{\mathrm{i}, \mathrm{st}}=0 \\
\text { (the right, or top, end of the strut) }
\end{array}
$$

From Figs. (1 and 2), $\mathrm{F}_{\mathrm{i}, \mathrm{st}}=2 \mathrm{P}_{\mathrm{i}, \mathrm{st}}$. Recall that Eq. 4 is still in terms of the total forces applied to the isolator rather than the axial forces in each strut.

Furthermore, Eq. 4 is in terms of the displacements at the corners of the plate. From continuity, the vertical displacement at a given corner is equal to the $\overline{\mathrm{X}}$ direction displacement at the end of the strut of the isolator attached at that corner. Specifically, $\mathrm{Z}_{\mathrm{O}}=$ $\mathrm{X}_{1, \mathrm{st}}(\mathrm{L}), \mathrm{Z}_{\mathrm{P}}=\mathrm{X}_{2, \mathrm{st}}(\mathrm{L}), \mathrm{Z}_{\mathrm{Q}}=\mathrm{X}_{3, \mathrm{st}}(\mathrm{L})$ and $\mathrm{Z}_{\mathrm{R}}=\mathrm{X}_{4, \mathrm{st}}(\mathrm{L})$. Substituting these relationships into Eq. 4, the following equations ensue:

$$
\begin{aligned}
& \mathrm{p}_{1, \mathrm{st}}+\mathrm{p}_{2, \mathrm{st}}+\mathrm{p}_{3, \mathrm{st}}+\mathrm{F}_{4, \mathrm{st}}=\mathrm{w} / 2 \\
& -\left(\mathrm{p}_{1, \mathrm{st}}+\mathrm{p}_{2, \mathrm{st}}\right) \mathrm{b}_{1}+\left(\mathrm{p}_{3, \mathrm{st}}+\mathrm{p}_{4, \mathrm{st}}\right) \mathrm{b}_{2}=0 \\
& \left(\mathrm{p}_{1, \mathrm{st}}+\mathrm{p}_{3, \mathrm{st}}\right) \mathrm{a}_{1}-\left(\mathrm{p}_{2, \mathrm{st}}+\mathrm{p}_{4, \mathrm{st}}\right) \mathrm{a}_{2}=0 \\
& \mathrm{x}_{1, \mathrm{st}}(1)+\mathrm{x}_{2, \mathrm{st}}(1)+\mathrm{x}_{3, \mathrm{st}}(1)+\mathrm{x}_{4, \mathrm{st}}(\mathrm{l})=0
\end{aligned}
$$

A computer program has been implemented as an interface to Mathematica, Ver. 5.2 (Wolfram Research, Inc. (2005)) to solve the system of differential Eqns. (14-19). Based on the given initial value of load, $p_{o}$, the implemented program solves for the value of the moment, $\mathrm{m}$ at the left end, or bottom, of the strut $(\mathrm{s}=0)$. Because of the nonlinearity of the system of equations, the solution is based on an iterative algorithm making use of the shooting method. The iteration is based on an initial guess for the moment, $\mathrm{m}$.

\section{Dynamic analysis}

\subsection{Dynamic analysis procedure}

Within the dynamic model the symmetric plate is assumed to be subject to a forced axial harmonic vibration as per Den Hartog (1985) (axial base displacement) as shown in Fig. 5. Similar to the static equilibrium analysis, the derivation of the equations of motion for the dynamic analysis is also divided into two parts. First, the equations of motion for the rigid plate are determined from the kinetic and potential energies in the system using Lagrange's equations. Second, the strut in each isolator is analyzed using D'Alembert's principle. All dynamic equations are liberalized for small motions and put in nondimensional form. A program written in Mathematica is used to numerically solve these equations to determine the motion transmissibility of the system.

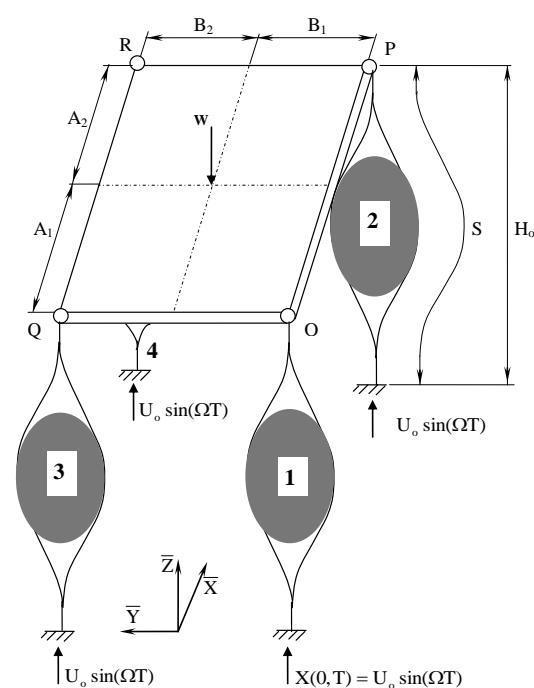

Fig. 5 The components Of model for the dynamic state

\subsubsection{Rigid plate analysis}

The $\bar{X}, \bar{Y}, \bar{Z}$ coordinate system is fixed in space as shown in Fig. 6 and has unit vectors $\hat{i}, \hat{j}$ and $\hat{k}$. The angles $\theta, \psi$ and $\phi$ are used to define coordinate rotations about the $\bar{X},-\bar{Y}$, and $\bar{Z}$ axes, respectively, and are initially zero. The points $\mathrm{O}, \mathrm{P}, \mathrm{Q}$, and $\mathrm{R}$ are located at the bottom of each corner of the plate, and the plate has an initial height $\mathrm{H}_{\mathrm{o}}$ when the system is in static equilibrium state. The center of mass (labeled c.m. in Fig. 6) is indicated by the dimensions $A_{1}, A_{2}$, $\mathrm{B}_{1}$, and $\mathrm{B}_{2}$, and it is positioned at a distance $\mathrm{C}^{\mathrm{C}}$ above the bottom of the plate.

The equations of motion for the plate will be determined using Lagrange's equations. Thus, it is necessary to determine the kinetic and potential energies of all components of the system. Because it is desirable to preserve symmetry in the model for the vibration isolator, horizontal springs are added to the corners of the plate to simulate the horizontal resistance contributed by the isolators when the plate rotates. Because this horizontal motion is very small, this assumption should have a minimal effect on the results of this analysis. The springs are numbered $1-8$ and attach to the plate as shown in Fig. 10.

The plate has both rotational and translational kinetic energy. The equations of motion for the plate become:

$$
\begin{gathered}
\mathrm{Y}_{\mathrm{Q}, \mathrm{d}}=\mathrm{Y}_{\mathrm{O}, \mathrm{d}} \\
\mathrm{X}_{\mathrm{P}, \mathrm{d}}=\mathrm{X}_{\mathrm{O}, \mathrm{d}} \\
\frac{-\mathrm{M} \Omega^{2}}{\mathrm{~A}_{1}+\mathrm{A}_{2}}\left[\mathrm{~A}_{2} \mathrm{X}_{\mathrm{O}, \mathrm{d}}+\mathrm{A}_{1} \mathrm{X}_{\mathrm{P}, \mathrm{d}}-\mathrm{CX}_{2, \mathrm{~d}}(\mathrm{~L})+\right. \\
\left.\mathrm{CX}_{1, \mathrm{~d}}(\mathrm{~L})\right]+\left(\mathrm{K}_{2}+\mathrm{K}_{3}\right) \mathrm{X}_{\mathrm{P}, \mathrm{d}}+\left(\mathrm{K}_{6}+\mathrm{K}_{7}\right) \mathrm{X}_{\mathrm{O}, \mathrm{d}}=0 \\
\frac{-\mathrm{M} \Omega^{2}}{\mathrm{~B}_{1}+\mathrm{B}_{2}}\left[\mathrm{~B}_{1} \mathrm{Y}_{\mathrm{Q}, \mathrm{d}}+\mathrm{B}_{2} \mathrm{Y}_{\mathrm{O}, \mathrm{d}}-\mathrm{CX}_{3, \mathrm{~d}}(\mathrm{~L})+\right. \\
\left.\mathrm{CX}_{1, \mathrm{~d}}(\mathrm{~L})\right]+\left(\mathrm{K}_{1}+\mathrm{K}_{8}\right) \mathrm{Y}_{\mathrm{O}, \mathrm{d}}+\left(\mathrm{K}_{4}+\mathrm{K}_{5}\right) \mathrm{Y}_{\mathrm{Q}, \mathrm{d}}=0
\end{gathered}
$$




$$
\begin{aligned}
& \frac{-M \Omega^{2}}{A_{1}+A_{2}}\left[A_{1} X_{2, d}(L)+A_{2} X_{1, d}(L)+C X_{P, d}-\right. \\
& \left.C X_{O, d}\right]-\frac{M \Omega^{2}}{A_{1}+A_{2}}\left[B_{1} X_{3, d}(L)-B_{1} X_{1, d}(L)+\right. \\
& \left.\mathrm{CY}_{\mathrm{Q}, \mathrm{d}}-\mathrm{CX}_{\mathrm{O}, \mathrm{d}}\right] \\
& =2\left[\mathrm{P}_{1, \mathrm{~d}}(\mathrm{~L})+\mathrm{P}_{2, \mathrm{~d}}(\mathrm{~L})+\mathrm{P}_{3, \mathrm{~d}}(\mathrm{~L})+\mathrm{P}_{4, \mathrm{~d}}(\mathrm{~L})\right] \\
& \frac{-\mathrm{I}_{\mathrm{X}} \Omega^{2}}{\mathrm{~B}_{1}+\mathrm{B}_{2}}\left[\mathrm{X}_{3, \mathrm{~d}}(\mathrm{~L})-\mathrm{X}_{1, \mathrm{~d}}(\mathrm{~L})\right] \\
& =-2\left[\mathrm{P}_{1, \mathrm{~d}}(\mathrm{~L})+\mathrm{P}_{2, \mathrm{~d}}(\mathrm{~L})\right] \mathrm{B}_{1}+2\left[\mathrm{P}_{3, \mathrm{~d}}(\mathrm{~L})+\mathrm{P}_{4, \mathrm{~d}}(\mathrm{~L})\right] \mathrm{B}_{2} \\
& \frac{-I_{Y} \Omega^{2}}{A_{1}+A_{2}}\left[X_{2, d}(L)-X_{1, d}(L)\right] \\
& =-2\left[\mathrm{P}_{1, \mathrm{~d}}(\mathrm{~L})+\mathrm{P}_{3, \mathrm{~d}}(\mathrm{~L})\right] \mathrm{A}_{1}+2\left[\mathrm{P}_{2, \mathrm{~d}}(\mathrm{~L})+\mathrm{P}_{4, \mathrm{~d}}(\mathrm{~L})\right] \mathrm{A}_{2}(30)
\end{aligned}
$$

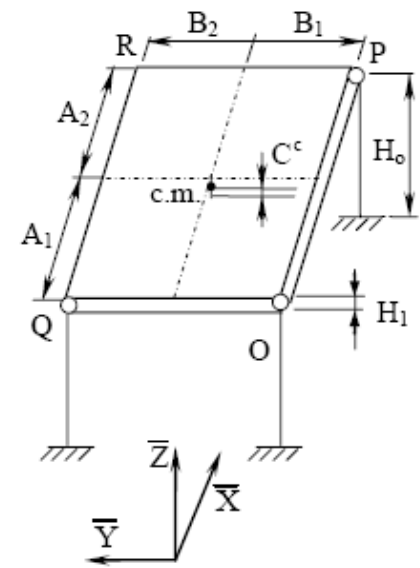

Fig. 6 Initial configuration of the plate

\subsubsection{Analysis of the vibration isolator}

In Den Hartog (1985) as well as in the present work the strut is assumed to take a horizontal position as shown in Fig. 7, such that the base lies at the left side of strut, at which the excitation force acts. Fig. 6 shows the isolator subjected to a harmonic base excitation $\mathrm{U}(\mathrm{T})$, where $\mathrm{U}(\mathrm{T})$ was defined as $\mathrm{U}(\mathrm{T})=\mathrm{U}_{\mathrm{o}} \sin (\Omega \mathrm{T})$. This imposed base displacement is resisted at the top of the isolator by the force $F_{i}$, which is now a portion of the combined effects of the weight $\mathrm{W}$ of the plate and the inertial load from the mass of the plate. In the analysis of the vibration isolator, it is again assumed that the horizontal movements $X_{O, d}, X_{P, d}, X_{Q, d}, X_{R, d}$, $Y_{O, d}, Y_{P, d}, Y_{Q, d}$, and $Y_{R, d}$ (generated by rotation angle $\theta$ about $\bar{X}$-axis and angle $\psi$ about $-\bar{Y}$-axis)at the corners of the plate are small enough that they can be neglected and symmetry can be used in the analysis of each isolator. It can be noticed that the deflection is a function of position along the strut, $\mathrm{L}$ and time, $\mathrm{T}$.

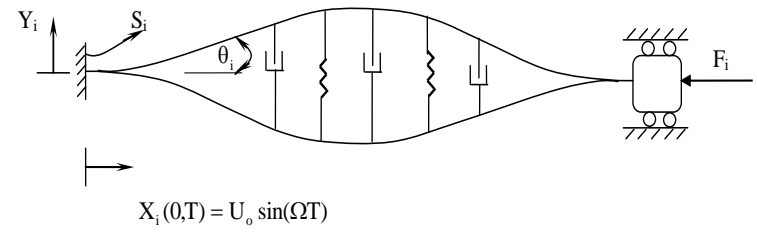

Fig. 7 Strut under forced harmonic vibration
In the present case we deal with linear viscous damping, i.e., the relationship between the damping force and the velocity of the system is linear. The analysis revealed that damping has a negligible effect on the transmissibility. The damping effect cannot be determined from geometrical, material, or other physical properties of the strut element. Hence, The damping effect can be determined through experiments such as a free vibration test. In any case, damping is present and must be taken into account.

To analyze the strut under forced harmonic excitation, a free body diagram of forces acting on an element at a particular time and position should be considered as shown in Fig. 8. This can be done by making use of D'Alembert's Principle, which is based on a fictitious inertia force that is set equal to the product of the mass and the acceleration. This force is assumed to act in the opposite direction of the accelerating mass. Hence, at any particular instant, the strut is considered to be in a state of static equilibrium Chopra (2001)

Notice that the mass per unit length $\mu$ of the strut is multiplied by the factor $\beta_{\mathrm{i}}$ that was used to adjust the bending stiffness EI in the equilibrium analysis. Assuming that the same material is used in each strut (i.e., the modulus of elasticity $\mathrm{E}$ remains constant), the bending stiffness can be modified by changing the cross-section of the strut so that the moment of inertia about the axis of bending becomes $\beta_{\mathrm{i}} \mathrm{I}$.

From the geometry, equilibrium, and the elastic constitutive laws for the strut, the following relationships can be established for the strut subjected to forced harmonic vibrations. The governing variables describing the strut can now be written as a function of time and location along the strut to describe the response of the strut to the forced excitation. The subscript "st" represents the static equilibrium portion of the equation, and " $\mathrm{d}$ " represents the dynamic portion, these equations are written below:

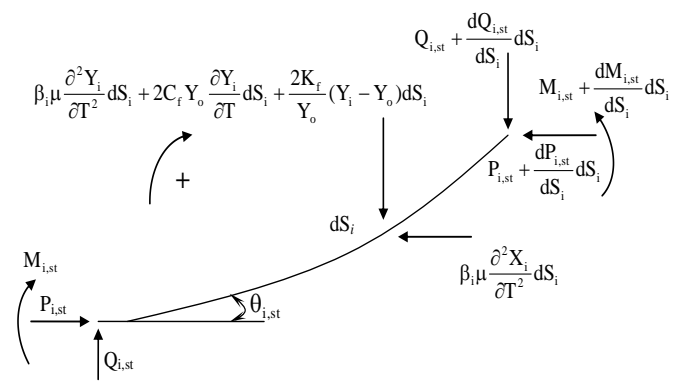

Fig. 8 Free body diagram of element of strut in dynamic state

$$
\begin{aligned}
& \frac{d X_{i, d}}{d S_{i}}=-\theta_{i, d} \sin \theta_{i, s t} \\
& \frac{d Y_{i, d}}{d S_{i}}=\theta_{i, d} \cos \theta_{i, s t}
\end{aligned}
$$




$$
\begin{aligned}
& \frac{d \theta_{i, d}}{d S_{i}}=\frac{M_{i, d}}{\beta_{i} E I} \\
& \frac{d M_{i, d}}{d S_{i}}=\left(Q_{i, d}-P_{i, s t} \theta_{i, d}\right) \cos \theta_{i, s t}- \\
& \left(P_{i, d}+Q_{i, s t} \theta_{i, d}\right) \sin \theta_{i, s t} \\
& \frac{d P_{i, d}}{d S_{i}}=\beta_{i} \mu \Omega^{2} X_{i, d} \\
& \frac{d Q_{i, d}}{d S_{i}}=\left[\beta_{i} \mu \Omega^{2}-i \Omega\left(2 C_{f} Y_{o}\right)-\frac{2 K_{f}}{Y_{o}}\right] . Y_{i, d}
\end{aligned}
$$

The variables describing the strut can now be written as a function of time and location along the strut to describe the response of the strut to the forced excitation. It is assumed that the dynamic vibrations will be relatively small. Hence, small displacement theory can be used to derive the following linear dynamic relationships. These equations are written below in non-dimensional form:

$$
\begin{aligned}
& \mathrm{y}_{\mathrm{Q}, \mathrm{d}}=\mathrm{y}_{\mathrm{O}, \mathrm{d}} \\
& \mathrm{x}_{\mathrm{P}, \mathrm{d}}=\mathrm{x}_{\mathrm{O}, \mathrm{d}}
\end{aligned}
$$

The equations of motion for the plate can be written as:

$$
\begin{aligned}
& -r w \omega^{2}\left[a_{2} x_{O, d}+a_{1} x_{P, d}-c x_{2, d}(1)+\right. \\
& \left.\mathrm{cx}_{1, \mathrm{~d}}(\mathrm{l})\right]+\left(\mathrm{k}_{2}+\mathrm{k}_{3}\right) \mathrm{x}_{\mathrm{P}, \mathrm{d}}+\left(\mathrm{k}_{6}+\mathrm{k}_{7}\right) \mathrm{x}_{\mathrm{O}, \mathrm{d}}=0 \\
& \frac{-\mathrm{rw} \omega^{2}}{\alpha}\left[\mathrm{b}_{1} \mathrm{y}_{\mathrm{Q}, \mathrm{d}}+\mathrm{b}_{2} \mathrm{y}_{\mathrm{O}, \mathrm{d}}-\mathrm{cx}_{3, \mathrm{~d}}(\mathrm{l})+\right. \\
& \left.\mathrm{cx}_{1, \mathrm{~d}}(\mathrm{l})\right]+\left(\mathrm{k}_{1}+\mathrm{k}_{8}\right) \mathrm{y}_{\mathrm{O}, \mathrm{d}}+\left(\mathrm{k}_{4}+\mathrm{k}_{5}\right) \mathrm{y}_{\mathrm{Q}, \mathrm{d}}=0 \\
& -r w \omega^{2}\left[a_{1} x_{2, d}(1)+a_{2} x_{1, d}(1)+c x_{P, d}-\right. \\
& \left.\mathrm{cx}_{\mathrm{O}, \mathrm{d}}\right]-\frac{\mathrm{rw} \omega^{2}}{\alpha}\left[\mathrm{b}_{1} \mathrm{x}_{3, \mathrm{~d}}(\mathrm{l})-\mathrm{b}_{1} \mathrm{x}_{1, \mathrm{~d}}(\mathrm{l})+\right. \\
& \left.\mathrm{cy}_{\mathrm{Q}, \mathrm{d}}-\mathrm{cx}_{\mathrm{O}, \mathrm{d}}\right] \\
& =2\left[\mathrm{p}_{1, \mathrm{~d}}(\mathrm{l})+\mathrm{p}_{2, \mathrm{~d}}(\mathrm{l})+\mathrm{p}_{3, \mathrm{~d}}(\mathrm{l})+\mathrm{p}_{4, \mathrm{~d}}(\mathrm{l})\right] \\
& \frac{-\mathrm{i}_{X} \omega^{2}}{\alpha}\left[\mathrm{x}_{3, \mathrm{~d}}(1)-\mathrm{x}_{1, \mathrm{~d}}(1)\right] \\
& =-2\left[\mathrm{p}_{1, \mathrm{~d}}(\mathrm{l})+\mathrm{p}_{2, \mathrm{~d}}(\mathrm{l})\right] \mathrm{b}_{1}+2\left[\mathrm{p}_{3, \mathrm{~d}}(\mathrm{l})+\mathrm{p}_{4, \mathrm{~d}}(\mathrm{l})\right] \mathrm{b}_{2}(42) \\
& -\mathrm{i}_{\mathrm{y}} \omega^{2}\left[\mathrm{x}_{2, \mathrm{~d}}(1)-\mathrm{x}_{1, \mathrm{~d}}(1)\right]=-2\left[\mathrm{p}_{1, \mathrm{~d}}(\mathrm{l})+\mathrm{p}_{3, \mathrm{~d}}(\mathrm{l})\right] \mathrm{a}_{1}+ \\
& 2\left[\mathrm{p}_{2, \mathrm{~d}}(\mathrm{l})+\mathrm{p}_{4, \mathrm{~d}}(\mathrm{l})\right] \mathrm{a}_{2}
\end{aligned}
$$

Similarly, the dynamic equations for the strut can be written as:

$$
\begin{aligned}
\frac{\mathrm{dx}_{\mathrm{i}, \mathrm{d}}}{\mathrm{ds}_{\mathrm{i}}} & =-\theta_{\mathrm{i}, \mathrm{d}} \sin \theta_{\mathrm{i}, \mathrm{st}} \\
\frac{\mathrm{dy}_{\mathrm{i}, \mathrm{d}}}{\mathrm{ds}_{\mathrm{i}}} & =\theta_{\mathrm{i}, \mathrm{d}} \cos \theta_{\mathrm{i}, \mathrm{st}} \\
\frac{\mathrm{d} \theta_{\mathrm{i}, \mathrm{d}}}{\mathrm{ds}_{\mathrm{i}}} & =\frac{\mathrm{m}_{\mathrm{i}, \mathrm{d}}}{\beta_{\mathrm{i}}} \\
\frac{\mathrm{dm}_{\mathrm{i}, \mathrm{d}}}{\mathrm{ds}_{\mathrm{i}}} & =\left(\mathrm{q}_{\mathrm{i}, \mathrm{d}}-\mathrm{p}_{\mathrm{i}, \mathrm{st}} \theta_{\mathrm{i}, \mathrm{d}}\right) \cos \theta_{\mathrm{i}, \mathrm{st}}- \\
\frac{\mathrm{dp}_{\mathrm{i}, \mathrm{d}}}{\mathrm{ds}_{\mathrm{i}}} & =\beta_{\mathrm{i}} \omega^{2} \mathrm{x}_{\mathrm{i}, \mathrm{d}}
\end{aligned}
$$

$$
\frac{d q_{i, d}}{d s_{i}}=\left(\beta_{i} \omega^{2}-i \omega c_{f} y_{o}-\frac{k_{f}}{y_{o}}\right) \cdot y_{i, d}
$$

\subsection{The boundary conditions for dynamic state}

The boundary conditions at each end of the strut can be written in a non-dimensional form:

At $\mathrm{s}_{\mathrm{i}}=0 ; \quad \mathrm{x}_{\mathrm{i}, \mathrm{d}}=\mathrm{u}_{\mathrm{o}}, \quad \mathrm{y}_{\mathrm{i}, \mathrm{d}}=0$, and $\quad \theta_{\mathrm{i}, \mathrm{d}}=0$

(the left, or bottom, end of the strut)

At $\mathrm{s}_{\mathrm{i}}=1 ; \mathrm{y}_{1, \mathrm{~d}}=\mathrm{y}_{3, \mathrm{~d}}, \mathrm{y}_{2, \mathrm{~d}}=\mathrm{y}_{4, \mathrm{~d}}, \mathrm{y}_{1, \mathrm{~d}}=\mathrm{y}_{4, \mathrm{~d}}, \mathrm{y}_{2, \mathrm{~d}}=\mathrm{y}_{3, \mathrm{~d}}$ and $\theta_{i, d}=0 \quad$ (the right, or top, end of the strut)

Similar to the static solution, the governing differential equations can be implemented in Mathematica to solve for the dynamic transmissibility. The moment $\mathrm{m}_{\mathrm{st}}$ determined from the equilibrium analysis is used as initial value in the dynamic analysis to determine the dynamic transmissibility. Other known values of the initial load $p_{0}$, the amplitude of excitation at the base $\mathrm{u}_{\mathrm{o}}$, the stiffness parameter, $\mathrm{r}$, and the external damping parameter, $\mathrm{c}$, are defined and used as input in the program. Repeatedly, the iterative scheme based on the use of the shooting method is implemented to solve the equations; with the following initial variables $p_{d}(0), q_{d}(0)$, and $m_{d}(0)$. To increase the convergence, the resulting variables: $p_{d}(0), q_{d}(0)$, and $\mathrm{m}_{\mathrm{d}}(0)$, are updated by adding weighted percentage of their initial values, are then used as a guess for the next iteration in the loop.

The dynamic transmissibility of the system is the ultimate goal of this work. The equations used to determine the transmissibility is given below.

As mentioned before, we deal herein with a displacement transmissibility. The implemented algorithm is programmed again by Mathematica to solve for the real and imaginary parts of the solution.

$$
\begin{aligned}
& \mathrm{TR}_{\mathrm{i}}=\frac{\sqrt{\left\{\operatorname{Re}\left[\mathrm{x}_{\mathrm{i}, \mathrm{d}}(1)\right]\right\}^{2}+\left\{\operatorname{Im}\left[\mathrm{x}_{\mathrm{i}, \mathrm{d}}(1)\right]\right\}^{2}}}{\left|\mathrm{u}_{\mathrm{o}}\right|} \\
& \mathrm{TR}=\frac{\mathrm{TR}_{1}+\mathrm{TR}_{2}+\mathrm{TR}_{3}+\mathrm{TR}_{4}}{4}
\end{aligned}
$$

The square root of the sum of the squares (SRSS) of the real and imaginary eigen values are used to calculate the displacement of the strut at the top under the acting dynamic load. The SRSS is then divided by the original amplitude of the base, $u_{o}$, to determine the dynamic transmissibility. Because each strut underlies the same amplitude and frequency, the dynamic transmissibility calculated at the top of each strut is the same at the center of the rigid plate.

\section{Results and Discussion}

Using the Mathematica program, the equations of motion derived in this research for the system are numerically solved. The system is analyzed for the fully symmetric case, i.e., the center of mass is positioned at the geometric center of the plate, as shown in Fig. 9. 


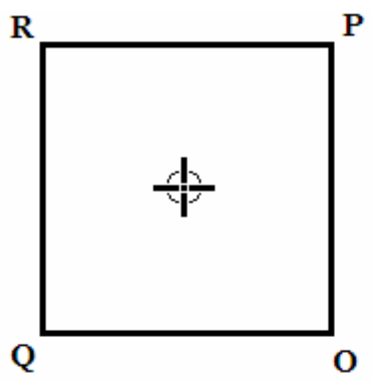

Fig. 9 Location of the center of mass

The transmissibility is computed and plotted for a wide range of non-dimensional excitation frequencies. The transmissibility plots are used to recognize frequencies at which resonance occurs in the system and frequency ranges in which the transmissibility is small.

The equations of motion are solved for the case shown in Fig. 9. The non-dimensional weight $\mathrm{w}$ is set at 320 , as was done in the equilibrium analysis. Similarly, the stiffness $\mathrm{k}_{\mathrm{j}}$ of the eight horizontal springs attached to the plate are each set at 0.1 as shown in Fig. 10. The aspect ratio $\alpha$ of the plate is set equal to 1 , i.e. the plate remains square in this analysis. This will allow for a special case of symmetry to be analyzed which only exists for a square. The plate dimension $h_{1}$, required to calculate the vertical distance $c^{c}$ to the center of mass and the mass moments of inertia, $i_{x}$ and $\mathrm{i}_{\mathrm{y}}$, are set equal to 0.05 . The stiffness modification factor $\beta_{\mathrm{i}}$ for the symmetric plate was assumed equal to 1 and the equilibrium portion of the axial force $\mathrm{p}_{\mathrm{i}, \mathrm{st}}$, the shear force $\mathrm{q}_{\mathrm{i}, \mathrm{st}}$, and the bending moment $\mathrm{m}_{\mathrm{i}, \mathrm{e}}$ for each strut are obtained from the equilibrium analysis. From the solution of the equations of motion, the transmissibility TR is calculated for various excitation frequencies $\omega$ using Eqns. (50 and 51).

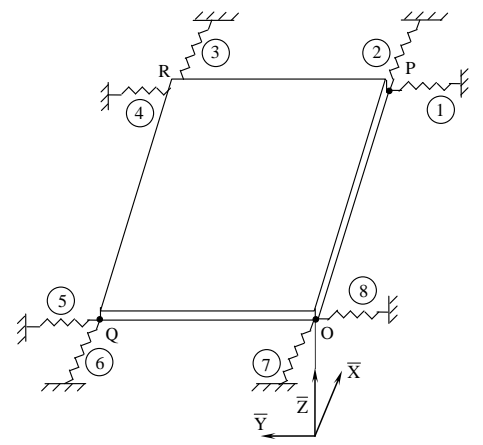

Fig. 10 Horizontal springs attached to plate

The system is analyzed for the case where the center of mass is located at the geometric center of the plate, as shown in Fig. 9. To do this, the nondimensional variables $a_{1}$ and $b_{1}$ are both set as 0.5 in the program. Because of the symmetry, the plate does not rotate and there is allowed movement in $\mathrm{Y}$ direction for this case.

\section{a. For static state}

Before the dynamic results is discussed, it is helpful to see how the different values of the amplitude of the deflection of the pre-bent struts, $a_{0}$, the initial static load, $\mathrm{p}_{\mathrm{o}}$, and the filler stiffness, $\mathrm{k}_{\mathrm{f}}$, affect the equilibrium shape of the struts. From Eq. 6, the maximum initial deflection at mid-height of the struts can be determined for each of these values of $a_{0}$. For $a_{0}$ $=0.01, \mathrm{y}_{\text {omax }}=0.00318 ;$ for $\mathrm{a}_{\mathrm{o}}=0.05, \mathrm{y}_{\text {omax }}=0.0159$; and for $\mathrm{a}_{\mathrm{o}}=0.1, \mathrm{y}_{\text {omax }}=0.0318$. These values are normalized by the strut length, therefore the largest amplitude of $\mathrm{a}_{0}=0.1$ provides a maximum initial deflection of the strut at its midpoint equal to approximately $3.2 \%$ of its length. This doesn't seem like a very large deflection, but after the struts are loaded statically with a value of $\mathrm{p}_{\mathrm{o}}=40$, the deflection at midheight of the strut is 0.24 (i.e., $24 \%$ of the strut length) for $\mathrm{a}_{\mathrm{o}}=0.1$ and $\mathrm{a}$ filler stiffness $\mathrm{k}_{\mathrm{f}}=0.1$. Therefore, the maximum $a_{o}$ to be used in the dynamic analysis is 0.1 . The moment and shear force acting on the struts in equilibrium state are equal for both struts. Their values are calculated $(\mathrm{m}=4.83007$ and $\mathrm{q}=$ $5.967 * 10^{-7}$ )

It is worth to mention that the direction of the buckled struts for the symmetric case can be outwards or inwards, as shown in Fig. 11. By giving positive value for $\mathrm{m}_{1}$ and a negative value for $\mathrm{m}_{2}$, the struts buckle outwards. By reversing the sign of the initial values the struts buckled inwards. The magnitude of the equilibrium moment and shear force doesn't change in case of inward buckling.

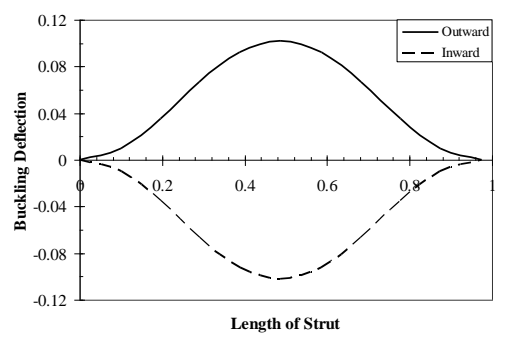

Fig. 11 The buckled struts for the equilibrium symmetric case

b. For dynamic state

The resonance frequencies represent an essential characteristic of the system. A resonance frequency can be determined by locating a frequency at which an undamped system's transmissibility is infinite. By setting the value of the external damping parameter $\mathrm{c}$ equal to zero, the un-damped case can be analyzed and the resonance frequencies can be found. When the transmissibility is plotted versus the non-dimensional frequency, $\omega$, the resonance frequencies are easily identified in the un-damped case by the highest peaks on the plot.

First the transmissibility was determined for the values of the filler stiffness, the case of $\mathrm{k}_{\mathrm{f}}=0.1, \mathrm{p}_{\mathrm{o}}=$ $40, \mathrm{a}_{\mathrm{o}}=0.1, \mathrm{c}=1.0$, and $\mathrm{r}=1.0$, in order to study the effects of the filler stiffness is plotted against the frequency in Fig. 12. By observing this plot, it is interesting to note that even though the stiffness of the strut was constant by one.

The transmissibility of the system is calculated for a range of non-dimensional applied frequencies from 0.01 to 200 . The case is plotted against the frequency in Fig. 12. As can be seen, four peaks of the transmissibility are indicated. These peak frequencies are located at $\omega=8.1,47.0,80.0$, and 142.0, respectively. Between each of these peaks, the 
transmissibility drops well below unity for a wide range of excitation frequencies. The region between the first and second peak is of particular interest because it is likely that this isolation device would be used to isolate vibrations in this range of frequencies. Then the transmissibility is less than unity from $\omega$ (30.0 to 44.0), $\omega(53.0$ to 77.0$), \omega(81.0$ to 134.0$)$ and $\omega(150.0$ to 200.0). After $\omega=200.0$ the isolation is good because the transmissibility less than unity.

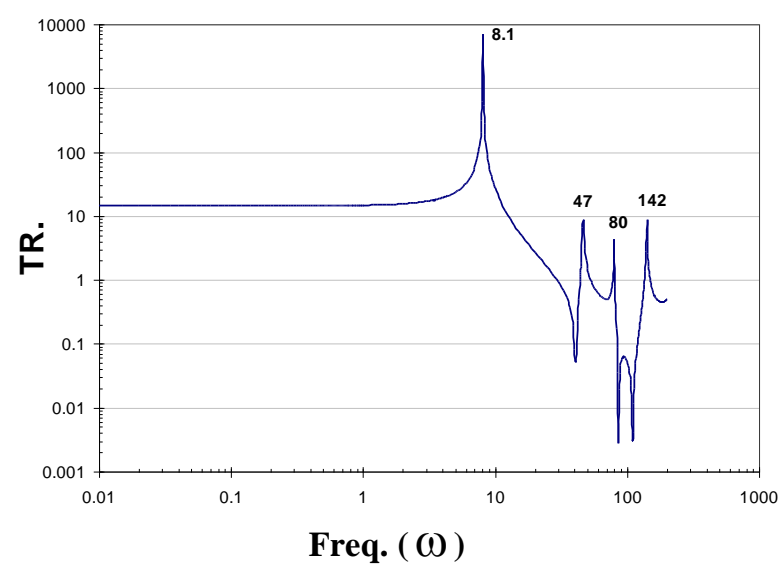

Fig. 12 Transmissibility vs. frequency for symmetric plate case with allowinga lateral motion of the rigid plate by two struts with filler in each corner, case $\left(a_{1}=0.5, b_{1}=0.5\right)$

The transmissibility vs. frequency for the symmetric plate case with allowing a lateral motion of the rigid plate supported by two struts at each corner and without filler is shown in Fig. 13. When observing the transmissibility plots in Figs 12 and 13, they look quite similar. They each have four significant frequency peaks.

The transmissibility vs. frequency for the symmetric plate case with allowing a lateral motion of the rigid plate supported by pair struts at each corner with and without filler is shown in Fig. 14. Transmissibility vs. frequency for the symmetric plate case without allowing a lateral motion of the rigid plate by pair struts with filler at each corner, case $\left(\mathrm{a}_{1}=\right.$ $\left.0.5, b_{1}=0.5\right)($ Jeffers $(2005))$.

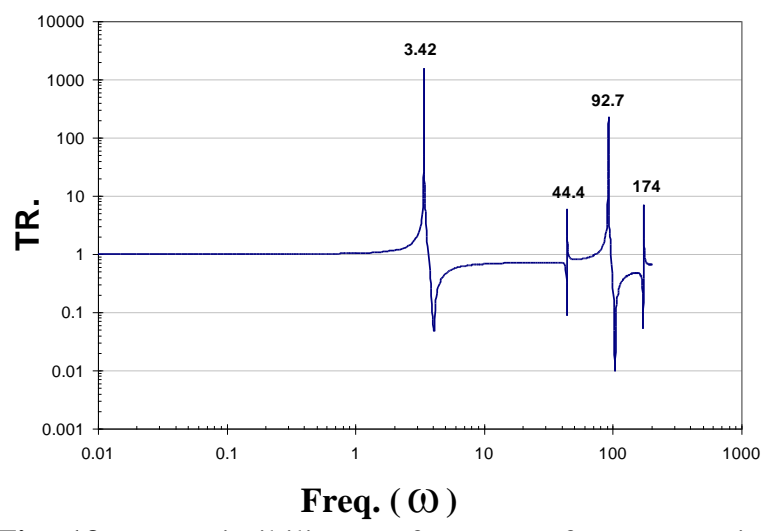

Fig. 13 Transmissibility vs. frequency for symmetric plate case with allowing a lateral motion of the rigid plate by two struts without filler in each corner, case $\left(\mathrm{a}_{1}=0.5, \mathrm{~b}_{1}=0.5\right)$

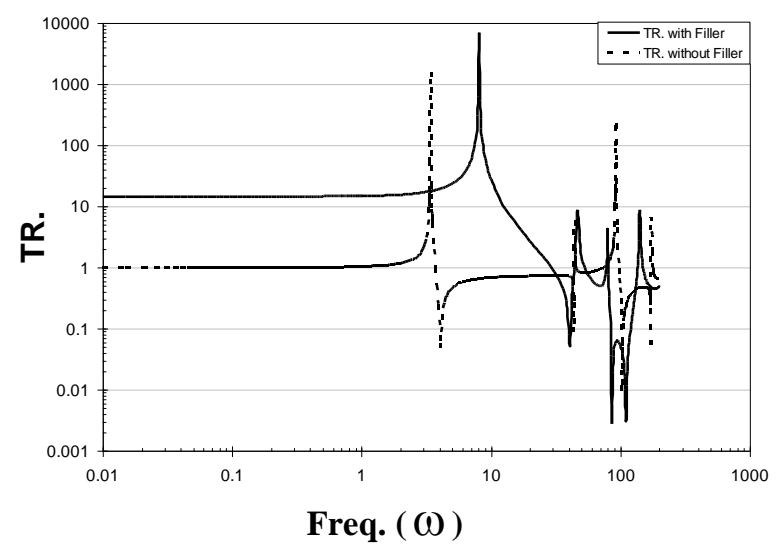

Fig. 14 Transmissibility vs. frequency for symmetric plate case with allowing a lateral motion of the rigid plate by pair struts with and without filler in each corner, case $\left(a_{1}=0.5, b_{1}=0.5\right)$

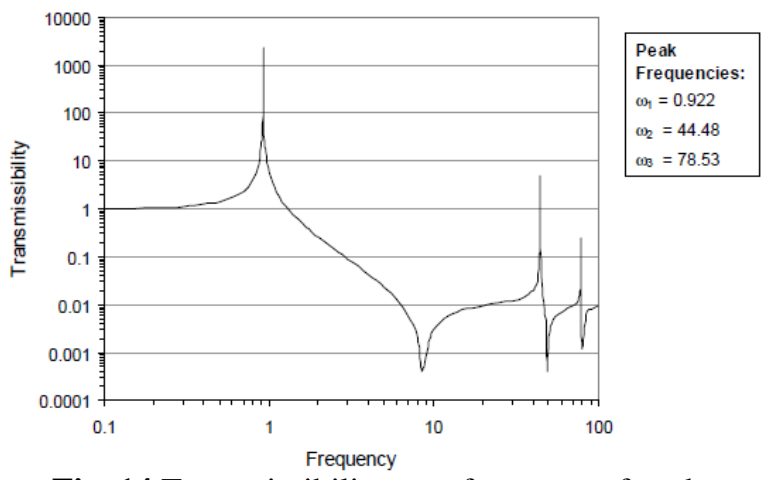

Fig. 14 Transmissibility vs. frequency for the symmetric plate case without allowing a lateral motion of the rigid plate by two struts in every corner, case $\left(a_{1}=0.5, b_{1}=0.5\right)$, Jeffers $(2005)$

As shown in figs $12-15$ and tables 1, 2 the transmissibility peaks in the case of allowed lateral motion of the plate, which supported by four pairs strut with filler are located at higher frequencies than those of without filler and without lateral motion. Table 1 shows the peak frequencies of vibration with allowing lateral motion by using four pairs of strut with intermediate bonded filler at each corner (case-a), with allowing lateral motion by using four pairs of strut without intermediate bonded filler at each corner (caseb) and without allowing lateral motion by using four pairs of strut with intermediate bonded filler at each corner (case-c)

From table 1 it is evident that the peak frequencies $\omega_{1}$ and $\omega_{3}$ are higher in case of our calculation with the existing of lateral motion than the corresponding values calculated in (Jeffers (2005)) without lateral motion. To further illustrate the increase in each of the frequency peaks for the different cases, the results have been tabulated for comparison in table 1 .

Each peak frequency that occurred in the range of frequencies studied has been named in order from the lowest, $\omega_{1}$, to the highest, $\omega_{4}$. The deviation of the peak frequency at $\omega_{1}$ equals $88.5 \%$. At $\omega_{3}$ the deviation is $1.875 \%$.

Table 2 shows the transmissibility of vibration with allowing lateral motion by using four pairs of strut with intermediate bonded filler at each corner (case-a), with allowing lateral motion by using four pairs of strut 
without intermediate bonded filler at each corner (caseb) and without allowing lateral motion by using four pairs of strut with intermediate bonded filler at each corner (case-c).

To further illustrate the increase in each of the frequency peaks and the transmissibility for the different cases, the results have been tabulated for comparison in tables 1 and 2. Each peak frequency that occurred in the range of frequencies studied has been named in order of the lowest, $\omega_{1}$, to the highest, $\omega_{3}$ and $\omega_{4}$. From table 2, the transmissibility at first, second and fourth peaks frequency in case-a are larger than in case-b and case-c but the transmissibility at third peaks frequency in case-a is smaller than in case$\mathrm{b}$ and case-c.

Table 1 Peak frequencies for three cases ( $a, b$ and c),

\begin{tabular}{|c|c|c|c|c|}
\hline Case & $\left.\mathrm{a}_{1}=0.5, \mathrm{~b}_{1}=0.5\right)$ & $\omega_{2}$ & $\omega_{3}$ & $\omega_{4}$ \\
\hline $\begin{array}{c}\text { Case (a) with filler (with } \\
\text { lateral) }\end{array}$ & 8.10 & 47.0 & 80.0 & 142 \\
\hline $\begin{array}{c}\text { case (b) without filler } \\
\text { (with lateral) }\end{array}$ & 3.42 & 44.4 & 92.7 & 174 \\
\hline $\begin{array}{c}\text { case (c) with filler } \\
\text { (without lateral) }\end{array}$ & 0.92 & 44.5 & 78.5 & ---- \\
\hline
\end{tabular}

as per Jeffers (2005)

Table 2 Transmissibility of vibrations for three cases

\begin{tabular}{|c|c|c|c|c|}
\hline (a, b and c), $\left(\mathrm{a}_{1}=0.5, \mathrm{~b}_{1}=0.5\right)$ & $\mathrm{TR}_{1}$ & $\mathrm{TR}_{2}$ & $\mathrm{TR}_{3}$ & $\mathrm{TR}_{4}$ \\
\hline $\begin{array}{c}\text { Case (a) with filler (with } \\
\text { lateral) }\end{array}$ & 6945 & 8.72 & 4.11 & 8.75 \\
\hline $\begin{array}{c}\text { case (b) without filler } \\
\text { (with lateral) }\end{array}$ & 1565 & 5.96 & 227.4 & 6.53 \\
\hline $\begin{array}{c}\text { case (c) with filler } \\
\text { (without lateral) }\end{array}$ & 1043 & 5.1 & 0.23 & ---- \\
\hline
\end{tabular}

\section{Conclusions}

The proposed isolation device has the ability to support a relatively large static load with a relatively small static deflection than the traditional vibration isolators and offers a low axial resistance under dynamic excitation, making it ideal for isolating vertical vibrations. By examining the results of model described, the following conclusions can be drawn:

- The use of post-buckled struts as vibration isolators provides a wide range of frequencies at which the transmissibility is well below unity,

- The direction of the horizontal deflection of the buckled struts, whether inwards or outwards, has no effect on the equilibrium moment and shear force and in turn on the transmissibility.

- Tuned isolators can provide improved vibration isolation, even lateral motion is allowed.

- The transmissibility doesn't differ substantially in shape. This is true if lateral motion is allowed or not. However, lateral motion improves the magnitude of transmissibility, and respectively the efficiency of vibration isolation, especially at high frequencies.
- The transmissibility at any point on the transmissibility vs. frequency curves other than the peak frequencies are well below 1 .

- It is apparent that the behavior of the ideal case of the model presents the best situation for utilizing post-buckled struts as vibration isolators.

- The transmissibility peaks in the case of allowed lateral motion of the plate are located at higher frequencies than those of without lateral motion.

- Several things were also learned about the model presented - pre-bent pairs of struts with an intermediate bonded filler. Filler stiffness would have to be chosen based on the requirements of both the static and dynamic behavior of the system.

- The presence of the Filler increases the transmissibility at lower frequencies and higher frequency $\left(\omega_{4}\right)$. But decreases the transmissibility at frequency $\left(\omega_{3}\right)$.

\section{References}

1 Alloway, L.A.: Analysis of buckled columns and rigid-link mechanisms used as vibration isolators. M. E. Report, Virginia Tech (2003)

2 Banik, R. and Gweon, D.G.: Design of six degree of freedom hybrid active-passive vibration isolator using voice coil actuator. Int. J. Nanomanufacturing, Vol. 1, No. 6, pp.771-783 (2008)

3 Britvec, S.J.: The Stability of Elastic Systems. p. 190, Pergamon Unified Engineering Series, Oxford (1973)

4 Carrella, A., Brennan, M.J., and Waters, T.P.: Static analysis of a passive vibration isolator with quasi-zero-stiffness characteristic. J. Sound Vib. 301 pp.678-689, doi:10.1016/j.jsv.2006.10.011 (2007)

5 Carrella, A., Friswell, M.I., Zotovb, A., Ewins, D.J., and Tichonov, A.: Using nonlinear springs to reduce the whirling of a rotating shaft. Mechanical Systems and Signal Processing 23, pp.2228-2235 (2009)

6 Chopra, A. K.: Dynamics of Structures-Theory and Applications to Earthquake Engineering. $2^{\text {nd }}$ edn, Prentice Hall, Upper Saddle River, New Jersey, 01 (2001)

7 Den Hartog, J.P.: Mechanical vibrations. Dover Publications, New York (1985)

8 Dickens, J.D. and Norwood, C.J.: Universal method to measure dynamic performance of vibration isolators under static load. J. Sound Vib. 244(4), pp.685-696, doi:10.1006/jsvi.2000.3516 (2001)

9 El-Kafrawy, A. et al.: Vibration isolation of a symmetric and asymmetric rigid bar using struts subject to axial static and dynamic excitation. Proc. IMechE Vol. 225, Part C, pp.334-346, DOI:101243/09544062JMES2125 (4 May 2010)

10 El-Kafrawy, A. et al.: (28 September 2010) Vibration isolation of a symmetric rigid plate using struts subject to axial static and dynamic 
excitation. Int. J. Mech. Mater Des, DOI 10.1007/s10999-010-9135-1, Springer (28 September 2010)

11 Favor, H. M., Plaut, R. H., Via, C. E.: Twodimensional Analysis of Vibration Isolation of Rigid Bar Supported by Buckled or Pre-bent Struts. Blacksburg, VA, December 3, (2004)

12 Huang, X., Elliott, S.J., and Brennan, M.J.: Active isolation of a flexible structure from base vibration. J. Sound Vib.263, pp.357-376, doi:10.1016/S0022-460X(02)01057-X (2003)

13 Ibrahim, R.A.: Recent advances in nonlinear passive vibration isolators. J. Sound Vib. 314, pp.371-452,doi:10.1016/j.jsv.2008.01.014 (2008)

14 Inman, D.J.: Engineering vibration. Prentice-Hall, Englewood Cliffs, NJ. Jalili, N., A new perspective for semi-automated structural vibration control (1994)

15 Jeffers, A.E., Plaut, R.H., and Via, C.E.: Vibration isolation of a horizontal rigid plate supported by Pre-bent Struts. Blacksburg, VA, December (2005)

16 Kovacica, I., Brennanb, M.J., and Waters, T.P.: A study of a nonlinear vibration isolator with a quasi-zero stiffness characteristic. J. Sound Vib. 315 pp.700-711, doi:10.1016/j.jsv.2007.12.019 (2008)

17 Liu, L.K., Zheng, G.T., Huang, W.H.: Octo-strut vibration isolation platform and its application to whole spacecraft vibration isolation. J. Sound Vib. 289, pp.726-744, doi:10.1016/j.jsv.2005. 02.040 (2006)

18 Plaut, R.H., Alloway, L.A., and Virgin, L.N. : Nonlinear oscillations of a buckled mechanism used as a vibration isolator. In: Proceedings of the IUTAM Symposium on Chaotic Dynamics and Control of Systems and Processes in Mechanics, Rome, Italy, Vol.122, 241-250 (2003)

19 Plaut, R.H., Sidbury, J.E., and Virgin, L.N.: Analysis of buckled and pre-bent fixed-end columns used as vibration isolators. J. Sound Vib. 283, pp.1216-1228, oi:10.1016/j.jsv.2004.07.029 (2005)

20 Serrand, M. and Elliott, S.J.: Multichannel feedback control for the isolation of base-excited vibration. J. Sound Vib. 234(4), pp.681-704, doi:10.1006/jsvi.2000.2891 (2000)

21 Sidbury, J.E.: Analysis of buckled and pre-bent columns used as vibration isolators, M.Sc. Thesis, Virginia Polytechnic Institute and State University, Blacksburg, VA, (2003)

22 Virgin, L.N.: The dynamics of symmetric postbuckling. Int. J. Mech. Sci. 27, 235-248, (1985)

23 Virgin, L.N., Davis, R.B.: Vibration isolation using buckled struts. J. Sound and Vib. 260, 965973 (2003)

24 Wolfram Research, Inc.: Mathematica, Version 5.2.0.0. Champaign, IL 61820 USA (2005)

25 Yilmaz, C., Kikuchi, N.: Analysis and design of passive low-pass filter-type vibration isolators considering stiffness and mass limitations. J. Sound Vib. 293, pp.171-195, doi:10.1016/j.jsv. 2005.09.016 (2006)
26 Zhou, N. and Liu, K.: A tunable high-static-lowdynamic stiffness vibration isolator. J. Sound Vib. 329 pp.1254-1273, doi:10.1016/j.jsv.2009.11.001 (2010) 